\title{
ESTA ES LA VICTORIA QUE HA VENCIDO
}

Con este motto que hemos puesto por título, cuya versión original es HAEC EST VICTORIA QVAE VINCIT (I JN 5,4), queremos en este nuevo número de IMAGO. REVISTA DE EMBLEMÁTICA Y CULTURA VISUAL, que va ya por el número 6, expresar en forma emblemática el sentido de esta revista y por extensión el sentido mismo que tiene la Sociedad Española de Emblemática (SEE). Es en realidad el motto de un jeroglífico que procede del altar efímero levantado en la parroquia de Santo Tomás de Valencia con ocasión de celebrarse el Cuarto Centenario de la Conquista de la ciudad por el rey don Jaime I, y que ha sobrevivido gracias al memorial impreso que nos ha legado Marco Antonio Ortí (Siglo Qvarto de la conquista de Valencia [...], Valencia, Juan Bautista Marçal, p. 36v). Reproducimos este jeroglífico en el reverso de la edición impresa, el cual nos muestra enfrentados dos gallos, robusto uno de ellos, señalado con la figura del sol, imponiéndose sobre el que tiene enfrente, señalado por la luna y con la cabeza inclinada como signo de reconocimiento. He aquí pictura y suscriptio:

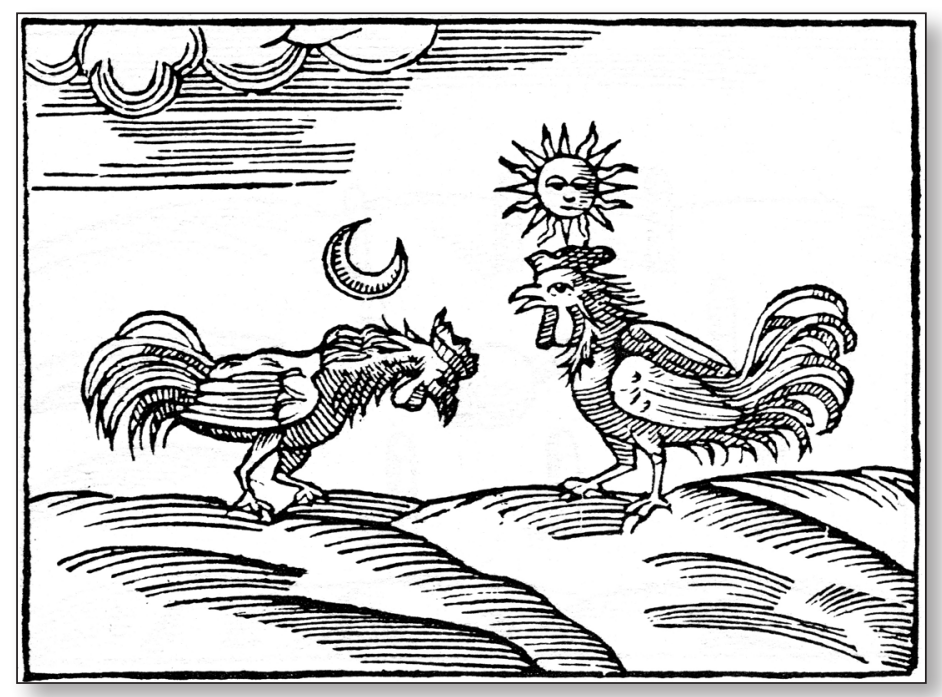

No se podrán tus ensayos Contra mi valor lograr, Pues no puedes alumbrar Sin valerte de mis rayos. 
En su momento fue un «artificio conceptuoso», como diría Gracián, que básicamente singularizaba la conquista cristiana, triunfante sobre el infiel, si bien llegaría a connotar otros sentidos en relación con las circunstancias del momento de esta celebración y de su contexto. También hoy, el hecho de haber sido elegido este jeroglífico para este lugar, y por tanto habiendo variado nuevamente el contexto, se presta a otras muchas significaciones connotadas según la sensibilidad de cada intérprete. Valga mantener, no obstante, que la intención de la Redacción de la revista es la de afirmar la presencia de ésta como un órgano hegemónico de la investigación sobre emblemática y la cultura visual, aspecto que también es aplicable a la misma SEE, cuya vitalidad, en el conjunto de la investigación desarrollada en la universidad española, está caracterizada por un continuo crecimiento. Cabrán otras lecturas de este jeroglífico con clave también actual, ¡seguro! Mas esta apertura de las posibilidades interpretativas es justamente una de las grandezas de la comunicación poética... y hay que dejar así las cosas.

De la vitalidad de esta sociedad, a parte de la revista IMAGO, es un importante indicio la serie de congresos bianuales, de los cuales está ya vigente el $X$ Congreso Internacional de la SEE, que lleva por título: Encrucijada de la palabra y la imagen, Palma de Mallorca 17-19 de diciembre de 2015.

El presente número lo conforman una serie de artículos de contrastada calidad, tanto de jóvenes investigadores como de figuras destacadas con una trayectoria reconocida. Una aportación, de entre los primeros, suele ser destacado en primer lugar en la portada, lo cual no sólo debe entenderse como signo de apoyo a sólidos investigadores emergentes, también porque así conviene a IMAGO, entendida tal cosa como un recurso de proyección de la misma revista. En este sentido, ha sido destacado el artículo "Los ángeles de la Lonja de los Mercaderes de Valencia», de Candela Perpiñá, un interesante estudio sobre iconografía musical. Así mismo la primera parte de "On the Origins of Spanish Hieroglyphs», del joven profesor brasileño Pedro Germano Leal, recientemente doctorado en la Universidad de Glasgow. Entre las colaboraciones de investigadores con trayectoria reconocida, cabe destacar, dentro de la sección de "notas»-dedicada especialmente a aprovechar aportaciones de prestigiosas personalidades de la SEE-, el impagable artículo: «Fuentes de información y recursos de utilidad para el estudio e investigación de la emblemática», preparado por la profesora Sagrario López Poza, que cuenta entre la nómina de socios fundadores y miembro de la presidencia de honor de la sEe. 